\title{
Arquitectura, del grafito al bit - nuevas interfaces, preguntas, retos ${ }^{1}$ I Arquitecture, from graphite to bit - new intrefaces, questions, challenges
}

\author{
Humberto Cavallín \\ (pág 157 - pág 170)
}

El uso de imágenes es históricamente inseparable de los procesos comunicacionales y decisionales en la formulación y resolución de problemas en el diseño arquitectónico. Con el desarrollo de las tecnologías digitales, han surgido debates cuestionando los escenarios de pensamiento y práctica arquitectónica, desde las prestaciones de los métodos de representación y simulación digitales. A partir estos debates, exploramos el impacto de estas dos modalidades de generación y uso de imágenes en términos de sus potenciales y limitaciones, así como las nuevas rutas a explorar en su uso en la solución de problemas de diseño.

Palabras clave: representación, arquitectura, diseño, resolución de problemas.

The use of images is historically inseparable and necessary to the communicational and decisional processes in the formulation and resolution of problems in architectural design. With the development of digital technologies, debates have arisen questioning the scenarios of architectural thought and practice, from the performance of digital representation and simulation methods. Starting from these debates, we explore the impact of these two modalities of generation and use of images in terms of their potentials and limitations, as well as the new routes to explore in their use in the solution of design problems in architectural design.

Keywords: representation, architecture, design, problem solving.

Humberto Cavallín es catedrático en la Escuela de Arquitectura de la Universidad de Puerto Rico, Recinto de Río Piedras, investiga acerca los aspectos y el uso de modelos para la formulación y resolución interdisciplinar de problemas de diseño en la arquitectura. Email de contacto, humberto.cavallin1@upr.edu.

Fecha de presentación: abril de 2019. Fecha de aceptación: junio de 2019. Fecha de publicación: diciembre de 2019 


\section{INTRODUCCIÓN}

Desde el inicio de la formalización del diseño arquitectónico como práctica durante el Renacimiento, la imagen ha sido un elemento central a la manera en la cual se le concibe y describe. Señalaba Alberti (1991, original 1755) que llamamos diseño a la organización que damos a las líneas y ángulos en nuestras mentes, y a los dibujos que hacemos para representar esas ideas. En ambos casos, la imagen aparece como generador (en la mente) y como documento (en el dibujo) que orienta y define la dirección de la solución del edificio. De una manera más radical, Peter Eisenman ha afirmado de una manera aún más radical que la arquitectura real solo existe en los dibujos (Ansari, 2013).

En los años recientes, y como señala Oxman (2017), el papel tradicional de la imagen visual en el diseño que se generaba de los trazos visuales del lápiz del diseñador se ha sustituido progresivamente hoy en día por los procesos algorítmicos de la computadora, y por las imágenes visuales generadas por los procesos computacionales propios de esas herramientas.

A principio de la década de los años 90's y como consecuencia del fenómeno producido por el desarrollo de las computadoras personales, la cantidad de computadoras en hogares y entornos de trabajo se ha multiplicado por diez, y la capacidad de procesamiento de datos que una vez se limitó a los gobiernos y a los grandes centros de investigación pasó a estar al alcance de cualquier persona que tuviese un pequeño capital para hacerse del equipo. Esta popularización de las computadoras personales y su creciente capacidad de procesamiento de datos permitió también que aplicaciones una vez destinadas a las grandes corporaciones, pudiesen llegar ahora a las mesas de las pequeñas oficinas de cualquier lugar del mundo. En el caso de la profesión arquitectónica, la adopción de las tecnologías de dibujo asistido por computadora sucedió prontamente. Su número creció exponencialmente durante esa década y las siguientes, y para el final del siglo XX era difícil visualizar ya la práctica de la profesión sin que estuviese involucrado algún componente digital en el proceso de diseño de edificaciones ${ }^{2}$, Ya señalaba Peter Eisenman (1992) que se vivía desde entonces un cambio de paradigma, que mutaba del mecánico prevaleciente desde el final de la Segunda Guerra Mundial, a uno signado por lo electrónico.

Los cambios acaecidos recientemente en los modos de práctica y en las tecnologías de producción e intercambio de información acerca del proyecto, han requerido una progresiva y rápida reeducación de los profesionales del diseño de edificaciones. En su discurso a la American Institute of Architects en 2005, Thom Mayne señalaba que los arquitectos "necesitan prepararse para una profesión que no van a reconocer en una década a partir de ahora, que es la que la próxima generación va a ocupar" (2005: 2) ${ }^{3}$. La introducción de lo digital en el taller de diseño arquitectónico ha tenido una historia que se extiende a las décadas finales del siglo XX. En la academia, esa introducción asumió la modalidad de lo que se llamó talleres sin papel (paperless studios), y que dio paso luego del desarrollo de Internet a la idea de estudios virtuales, y más recientemente a la idea de estudios globales apoyados por tecnologías digitales y el Internet (Ham \& Schnabel, 2011; Norman, 2001). Este desplazamiento del trabajo de resolución de problemas al mundo digital y las simulaciones virtuales, han facilitado la posibilidad de tener interacciones entre los participantes del proceso de diseño que no requieren de la fisicalidad, la co-presencia o la co-temporalidad propias del mundo análogo de décadas atrás. 
Por un lado, esto ha traído aportes significativos en el desarrollo de edificaciones cuya complejidad hubiese sido difícil de abordar solamente con el uso de imágenes generadas mediante el dibujo a mano tradicional. Por otro, estos nuevos tipos de modelos aportan niveles de información acerca de su proceso generativo comparado con el dibujo a mano caracterizado por acciones implícitas y un conocimiento no externalizado de manera explícita, en lo que Schön (1987) refiere como la conversación reflexiva con los materiales en el proceso. En este sentido, en los modelos generados de manera digital, la relación entre la imagen visual, los modos de razonamiento y las manipulaciones/acciones para generar esas imágenes quedan albergadas en los algoritmos que les generan, y son accesibles abierta a aquellos familiarizados con estos tipos de lenguajes de programación. A través del algoritmo, tenemos no solamente acceso a la producción de la imagen sino además a las manipulaciones y estructuras de conocimiento que le permitieron al diseñador generar los modelos y producir esas imágenes (Oxman, 2017). La imagen se convierte así en algo tanto infinitamente regenerable como potencialmente modificable/alterable en este proceso de generación, de una manera abierta y transparente para aquellos que conocen el lenguaje en el cual fueron codificados esos pasos, contrariamente al dibujo tradicional que es en esencia único y no regenerable.

Si bien la adopción de estas tecnologías luce actualmente como algo normalizado en la práctica del diseño arquitectónico y su presencia como algo esencialmente irreversible, estos cambios siguen levantando preguntas acerca del efecto que tienen en la manera en la cual se usan estas herramientas para formular y resolver problemas en el diseño, y el impacto que han tenido en el uso y desuso de otras herramientas previamente usadas en estos procesos, tales como el dibujo a mano, y en particular lo que se conoce como el sketch. Un aspecto importante del proceso de aprendizaje del diseño, y de la interacción entre diseñadores y otros profesionales, ha sucedido de manera tradicional en el mundo físico, intercambiando discursos y acciones usando para ellos dibujos y/o maquetas tangibles. Esta interacción se ha demostrado que es relevante a la transmisión de información, en la medida que colaboran para complementar el discurso explícito con acciones implícitas embebidas en esa interacción con los objetos.

Estaremos entonces discutiendo en este texto las diferencias que presentan estos avances digitales en relación con los procesos análogos del dibujo a mano, en tanto a por un lado la manera en la cual estas imágenes se generan y reproducen, y por otro al impacto que sus características de tangibilidad/intangibilidad afectan la experiencia del diseñador y su capacidad para resolver problemas en las diferentes etapas del diseño.
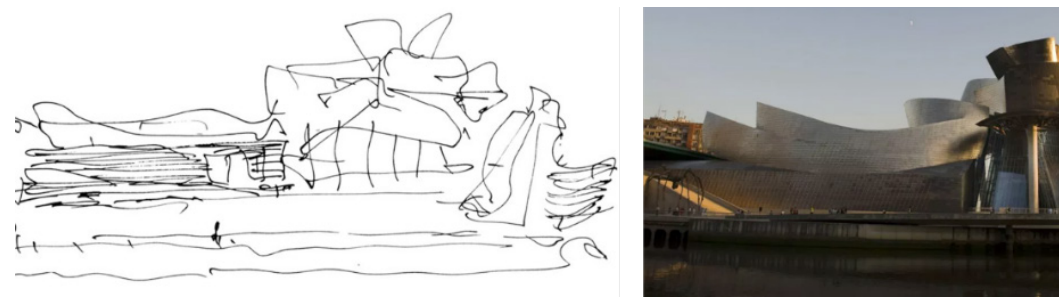

Figura 1: Dos imágenes del Museo Guggenheim de Bilbao. A la izquierda, un dibujo a mano de Frank Gehry en las etapas preliminares del proyecto y a la derecha una vista del edificio construido. El dibujo a mano muestra las características propias de imprecisión y ambigüedad que tiene el diseñador al inicio del proceso de diseño. 


\section{IMAGEN, DIBUJOS Y DISEÑO ARQUITECTÓNICO}

Para comprender el rol y el impacto que la imagen en sus diversas modalidades tiene en el proceso de diseño arquitectónico, consideramos importante discutir algunas características de la actividad de diseñar. El primer aspecto relevante a nuestra discusión es la naturaleza del tipo de problema con el cual se enfrentan los diseñadores. Los problemas de diseño se caracterizan por ser lo que Rittel (1988) denomina problemas endemoniados (o wicked problem como se le conoce en inglés), que se caracterizan como problemas en los cuales: 1) no existe una formulación definitiva de un problema endemoniado; 2) las soluciones a un problema endemoniado no son del tipo verdadero o falso, sino mejor o peor; 3) no existe ninguna prueba inmediata y definitiva de una solución a un problema endemoniado; 4) cada solución a un problema endemoniado es una "operación única"; 5) los problemas endemoniados no tienen un conjunto de soluciones potenciales definidas (o exhaustivamente posible de contar), ni tampoco existe un conjunto bien descrito de operaciones permitidas que pueden incorporarse al plan; 6) cada problema endemoniado es esencialmente único; 7) cada problema endemoniado puede considerarse como un síntoma de otro problema; 8) la existencia de una discrepancia representando a un problema endemoniado puede explicarse en varias formas, y de la elección de la explicación determina la naturaleza de la resolución al problema; y, 9) el diseñador no tiene derecho a equivocarse pues los diseñadores son responsables de las consecuencias de las acciones que generan (Rittel, 1971).

A fin de auxiliar el proceso requerido para resolver estos problemas endemoniados, los diseñadores usan herramientas para generar visualizaciones de sus ideas, que les permiten dialogar consigo mismo y con otros acerca de las expectativas de solución a los problemas. En ello, el uso de imágenes juega un rol central tanto en la formulación, framing ${ }^{4}$ y comunicación de las ideas de diseño. Como bien señala Mitchell citando a Aristóteles, "The soul never thinks without a mental image" (Aristóteles en "De Anima" citado por Mitchell, 1984). Si usamos a la clasificación que hace Mitchell de la imagen, el diseñador arquitectónico hace uso constante del rango de posibles instanciaciones de la imagen, de la imagen gráfica, a las simulaciones generadas por computadoras, a los modelos tridimensionales, a las evocaciones y el uso del lenguaje metafórico (Fig. 2). Señala Casakin (2017) en este sentido que el pensamiento del diseñador en el cual lo verbal y lo gráfico interactúan continuamente, el pensar en términos de metáforas y el uso de dibujos permite a los diseñadores no solamente entender y definir diversos aspectos del problema, sino que además son herramientas para comunicar y discutir estas soluciones a los otros actores que intervienen en el proceso de solución (Casakin \& Goldschmidt, 1999; Casakin, 2017; Lewis, 2000).

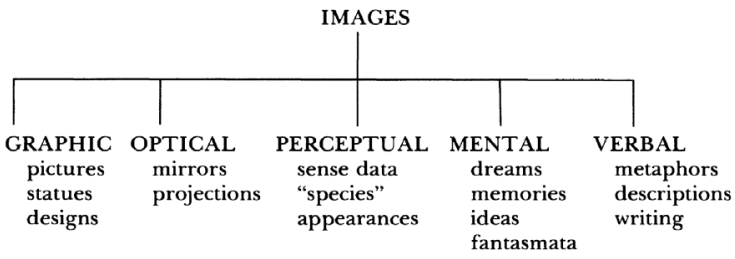


Desde esta perspectiva, y en términos del proceso de diseño, la imagen tiene al menos dos dimensiones cruciales en la formulación y resolución de problemas endemoniados. Por una parte, un rol en la dimensión individual del diseñador en el proceso de diseño, pues la imagen es herramienta y producto en la formulación, definición y solución del/al problema. Y por otra en la dimensión social en la medida que la imagen es una herramienta crucial en el intercambio de información entre los intervinientes en la formulación, proceso y solución al problema de diseño, facilitando/mediando estas interacciones.

En tanto la dimensión social del proceso de diseño del uso de las imágenes, ellas se convierten en herramientas esenciales en la interacción con las otras personas envueltas en el proceso. Por su naturaleza compleja y multidimensional, la formulación de los problemas endemoniados no es un proceso trivial, y por ello la formulación del problema como su ulterior resolución van a requerir de una visión compleja de la realidad en estudio que va a requerir de múltiples modelos y simulaciones, y de la colaboración de diferentes áreas de experticia. Rittel (1988) refería a esta necesidad de colaboración interdisciplinar en la resolución de problemas como algo que surge de lo que él denomina la existencia de simetrías de ignorancia:

[En la resolución de problemas endemoniados] la experticia y la ignorancia se encuentran distribuidas entre todos los involucrados en el problema. Existe una simetría de ignorancia entre aquellos que participan porque en virtud de sus títulos académicos o su status nadie conoce mejor que el otro acerca del problema por virtud de sus títulos académicos o su status (...) Nadie tiene una justificación suficiente para pretender que su conocimiento es superior al de cualquier otro participante. Ni existe ninguna razón lógica o de formación que permita decir que lo que yo sé es mejor de lo que tú sabes (Rittel, 1988: 325) .

El trabajo interdisciplinar surge como una respuesta a la necesidad de sumar las diversas experticias para el logro del fin común de resolver problemas (Rittel, 1965; Shermerhorn, Hunt, \& Osborn, 1995). Esta no es una suma aritmética en la cual las parcialidades de conocimiento de cada una de las disciplinas se añaden discretamente a las otras. Estas uniones van a estar mediadas por las características de los individuos involucrados en las organizaciones interdisciplinares, las creencias que éstos poseen, sus valores, y el contexto en el que la interacción tiene lugar, son todos ellos factores que van a afectar la dinámica de los grupos y su capacidad para formular y resolver problemas de manera exitosa (Handy, 1993). Esta diversidad va a hacer que cada participante pueda ver la situación problemática de manera diversa y en algunas instancias incluso conflictiva, por encontrarse cada uno de ellos ubicado en una visión de mundo/paradigmas que ha sido generada desde cada ámbito disciplinar en particular. 


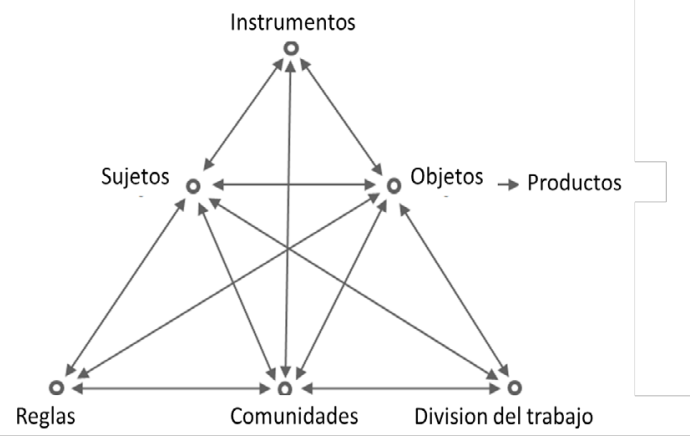

Figura 3: Triángulo de dimensiones consideradas por la Teoría de la Actividad según Engeström (Traducido de Engeström, Miettinen, \& Punamäki, 1999).

La moneda de cambio en estos procesos de interacción son las imágenes que los diversos actores intervinientes usan para que el otro pueda tener acceso a sus prefiguraciones de solución. Con conceptos de la teoría de la Teoría de la Actividad, desarrollada por Leóntiev, los cuales han sido usados con éxito para el estudio de actividades en el campo de investigación de interacciones entre seres humanos y computadoras (Albrechtsen, Andersen, Bødker, \& Pejtersen, 2001; Engeström et al., 1999; Kuutti, 1996), podemos ver las imágenes como objetos que median el conjunto de acciones mediadas (Figura 3), entre los sujetos y los objetos, insertos en un contexto que involucra herramientas, reglas y división social del trabajo.

En este aspecto de la resolución de los problemas de diseño, la sofisticación que las herramientas digitales han traído al discurso visual han sido contribuciones de indudable relevancia. Hoy en día, los programados digitales que añaden a las imágenes metainformación acerca de sus características materiales, económicas, entre otras, de los objetos representados, ha permitido un giro hacia la interdisciplinaridad que ha sido recogido ampliamente por las organizaciones profesionales, favoreciendo surgimiento del Integrated Project Delivery, ó IPD. Este proyecto se define como una forma de desarrollo que integra personas, sistemas y estructuras de negocios en un proceso colaborativo que une talentos y percepciones de todos los participantes a fin de reducir el gasto y optimizar la eficacia, a través de las diferentes fases del diseño, fabricación y construcción de las edificaciones (AIACC, 2014). Las herramientas que se utilizan en este desarrollo son los modelos de información de edificaciones (Building Information Modeling, ó BIM). Estas han ampliado las posibilidades de comunicación y simulación en el diseño de edificaciones, facilitando el compartir información acerca del proyecto entre los diferentes participantes en tiempo real, e incluso compartiendo un solo modelo de la edificación y no como ha sucedido por siglos de uso del dibujo en papel como medio de representación, el cual limitaba estos intercambios tanto en complejidad, como en simultaneidad y tiempo. Este impacto ha cambiado el escenario profesional y académico en el diseño arquitectónico, y las preguntas y posibilidades que estos generan. Adicionalmente, y como señalaba Oxman (2017), el uso de algoritmos en la generación de los objetos/imágenes en diseño permiten convertir a las imágenes generadas por los programas como los BIM o las aplicaciones de generación pa- 
ramétrica tales como Grasshopper, en entidades que pueden ser infinitamente regenerables y potencialmente modificable/alterable en este proceso de generación, en la medida en que la metainformación añadida a las imágenes permite alterar los pasos usados para su producción. Todos estos avances suponen una revolución en la arquitectura contemporánea, proveyendo un avance en el manejo de las formas complejas durante el proceso de diseño, y luego durante la construcción, que hubiese sido posiblemente imposibles de realizar sin la existencia de los recursos digitales.

En el espectro opuesto a la interacción social requerida por el proceso de diseño tenemos el trabajo individual realizado por el diseñador, para el cual la imagen pasa a ser tanto herramienta como producto requerido en la formulación, definición y solución del/ al problema. Schön (1992) refiere dos procesos complementarios que suceden alrededor de estos modelos: la conversación reflexiva con las situaciones y la conversación reflexiva con los materiales. Este segundo aspecto es crucial, en la medida en que los materiales (en este caso los dibujos, modelos, etc.) son, según Schön, mediadores en la formulación y resolución de los problemas. Estos dos procesos son cruciales en las acciones iniciales del proceso de diseño, cuando el diseñador está prefigurando tanto las características del problema como la formalización de la solución. Así, en el diseño la imagen funciona de una manera dual, en la medida que es un recurso para ayudar a hacer el framing del problema (con, por ejemplo, el uso de precedentes), pero también es la manera en la cual se prefigura la solución, mediante la representación de la idea. Pero como señala Schön, el dibujo del diseñador opera de una manera continuamente interactiva, informando y cambiando interactivamente durante su producción. Durante el proceso, se genera la imagen a la vez que se edita. Es lo que Schön llama una conversación reflexiva con los materiales (Fig. 4).

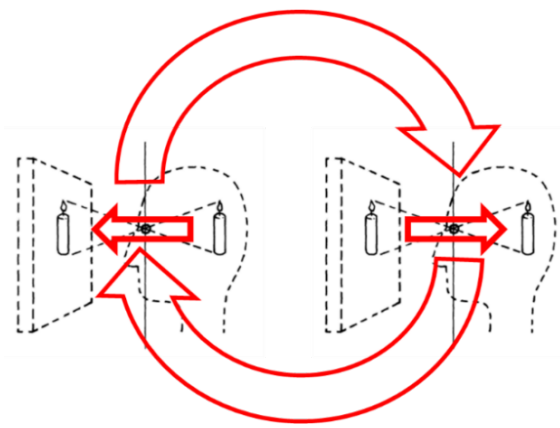

Figura 4: Esquema basado en la representación de la imagen en Mitchell (1984), alterado para representar el proceso de recurrencia de la mente a la imagen física y de vuelta a la mente, según la propuesta de conversación reflexiva con los materiales elaborada por Schön.

Esta conversación descrita por Schön es crucial para lograr una solución a los problemas del diseño. Como ha señalado Rittel (1988) al describir los problemas endemoniados y por consecuencia los problemas de diseño, al inicio los diseños son inherentemente ambiguos, pero con el paso del tiempo, el diseñador les va proveyendo sentido. El dibujo y las imágenes generadas al inicio del diseño son por ello 
imprecisos, ambiguos, y al mismo tiempo, en su imprecisión contienen una heurística que provee los caminos para su solución. Como señala Goldschmidt, estos dibujos y los modelos mentales generados a partir de ellos son:

mecanismos dinámicos que tiene una función heurística en el sentido de que proporciona información sobre estados pasados, actuales y futuros (...) Los modelos mentales nos ayudan a interpretar, explicar, anticipar y razonar sobre ideas, situaciones, eventos, el entorno y los objetos, guiando así nuestro comportamiento. También desarrollamos modelos mentales de nosotros mismos y de nuestra interacción con los demás y con los sistemas (Goldschmidt, 2017) ${ }^{6}$.

Como afirman Moore et al (2013), en estas primeras etapas los diseñadores usan una variedad de representaciones que interactúan entre sí. A menudo son imágenes inestables e incluyen nociones incompletas de la solución. El desarrollo de estas imágenes mediante los modelos mentales implica aumentar la fluidez representacional, así como el progreso paralelo e interactivo a lo largo de una variedad de dimensiones. Este proceso de disminución progresiva en la ambigüedad y el carácter difuso del problema de diseño mediante la prefiguración iterativa e interactiva con los modelos mentales es vital en el proceso creativo de los diseñadores. La imagen como hemos mencionado no solamente representa un 'algo' en el diseño, sino que al mismo tiempo presentan la posibilidad de observar, alterar, manejar lo representado, construyendo así, progresivamente, límites al problema y explorando opciones de solución.

Estas necesarias características de fluidez y ambigüedad se oponen claramente con las prestaciones de imagen que hemos resaltado como aportes relevantes de las imágenes generadas algorítmicamente y la capacidad de representación fotorrealista de los programados contemporáneos. Por un lado, programas como Autocad, Revit, Grasshopper o Sketchup (todos de gran aceptación en la arquitectura) requieren del diseñador niveles de precisión que rara vez tiene un diseñador en las etapas iniciales del proceso de diseño, tal y como lo hemos descrito hasta ahora. En este sentido, las virtudes de la imprecisión y la ambigüedad del dibujo a mano transfieren pobremente a lo requerido por las herramientas digitales. Como puntualiza Goldschmidt, la cognición humana no ha cambiado con el advenimiento de las computadoras y el acto de dibujar es una actividad propia de exploración, existiendo una correspondencia directa entre la novedad del problema a enfrentar y la utilidad de ciertas herramientas para las representaciones requeridas en cada etapa del proceso de solución de problemas y más específicamente en el caso de los problemas endemoniados en los cuales se requiere del pensamiento creativo y en el cual el dibujo a mano es una herramienta exploratoria esencial en el proceso de descubrir la solución de diseño, proveyendo claves intencionales y no intencionadas que regularmente el mouse y la computadora no pueden proveer (Goldschmidt, 2017). 
3. NUEVOS RETOS PARA LOS NUEVOS MEDIOS.

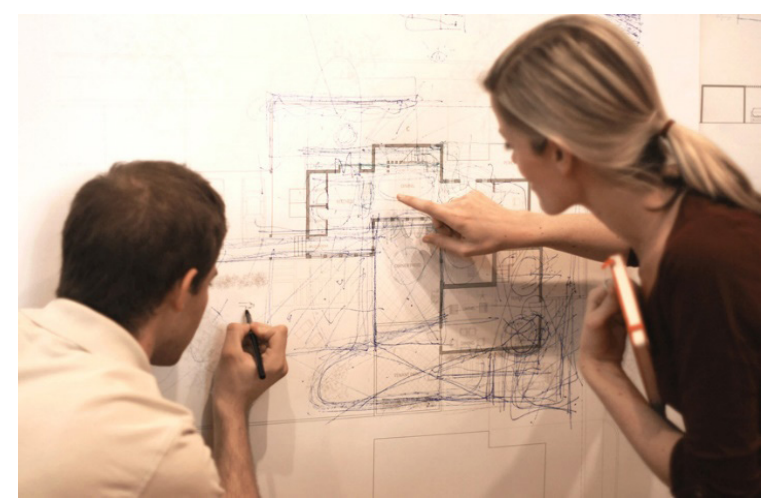

Figura 5: Interacción tradicional en el taller de diseño, involucrando dibujos, papeles de calco, y trazos realizados sobre ambos.

El interés en conciliar las posibilidades que el mundo digital contemporáneo ofrece con las necesidades propias de las diversas etapas del proceso de diseño nos has llevado a investigar acerca de cómo incorporar parte de esa experiencia tangible del sketch y el trabajo tradicional del dibujo a mano al mundo digital, a fin de poder compartir experiencias como las puntualizadas por Schön. Para ello, nos hemos focalizado en el aspecto que se conoce como "crítica de mesa", que es el proceso que sucede en los talleres de diseño cuando el profesor y el estudiante conversan acerca del proyecto. Durante la discusión, se utilizan los modelos que el estudiante ha ido. Específicamente, nos hemos concentrado en el proceso que involucra la conversación en torno a los dibujos como herramienta de diálogo y aprendizaje en el taller de diseño.

Con esta perspectiva teórica nos aproximamos al taller de diseño. Realizamos observaciones no participe de las sesiones de críticas de diseño, en las que documentamos las dimensiones señaladas por Engeström (Engeström et al., 1999). Estas observaciones nos permitieron identificar características que la interfaz digital debía poseer, a fin de preservar elementos necesarios a la dinámica de 'conversación con los objetos' señalada por Schön. Un aspecto importante que identificamos fue la necesidad de incorporar múltiples imágenes, ya fueran de dibujos como de otras imágenes que apoyan el proceso a modo de precedentes (por ejemplo, fotografías de proyectos previos, imágenes del proceso de diseño, etc.). Un segundo aspecto fue preservar la posibilidad de anotar esas imágenes usando líneas de diferentes características de grosor y color, que permitieran enfatizar y separar categorías en los dibujos realizados. Finalmente, enfocamos en la posibilidad de traer a la experiencia la translucencia del papel de calco, que permite intervenir en las interacciones añadiendo capas de análisis a la discusión mediante la superposición de los dibujos, a la vez que mantiene un relevante nivel de ambigüedad (Gaver, Beaver, \& Benford, 2003). La interacción análoga que se logró a través de la experiencia con el papel fue muy positiva, al compararla con la precisión requerida por las interacciones digitales tradicionales a través de los programas del tipo del Diseño Auxiliado por Computadoras ${ }^{7}$ (Computer Aided Design o CAD). 
Otros aspectos que consideramos relevantes como producto de estas observaciones fueron la necesidad de portabilidad a otras plataformas, dado la gran variedad de herramientas y sistemas operativos utilizados en los artefactos digitales incorporados cotidianamente al taller de diseño (computadoras, tabletas, teléfonos inteligentes). El reconocimiento de la importancia de lo tangible en el proceso de diseño ha sido un aspecto crucial para el desarrollo de las tecnologías digitales usadas por los diseñadores contemporáneos (Salama, 1995). Algunas tecnologías pioneras fueron el rayo lápiz y las tabletas activadas táctilmente (Barfield \& Furness, 1995). También está trabajo desarrollado por Ishii hacia el final del siglo XX con los tangible bits (Ishii, 2008; Ishii \& Ullmer, 1997). Este proceso ha tenido un avance relevante en años recientes gracias al desarrollo y expansión de las superficies táctiles de bajo costo (Han, 2005), y su incorporación a una enorme diversidad de equipos, desde computadoras, a teléfonos celulares.

Finalmente, fue importante para nosotros poder reproducir la experiencia física de la interacción entre los objetos y los demás, en un proceso que Figueroa (2015) describe de la siguiente manera:

[...] las implicaciones de asumir el concepto de esquema corporal y sus derivaciones aplicadas al campo de la actividad a través de artefactos de tecnología de comunicación digital abarcan varias áreas. En primer lugar, sugiere tomar en consideración el ambiente y las herramientas utilizadas como un medio de soporte de las interacciones dentro de su particular contexto sociocultural. Esto significa enfocar en la experiencia comunicativa y cómo se tejen las formas de interacción social a partir de las diferentes modalidades de comunicación. El énfasis en aspectos de comunicación y cognición contextualizada tiene relevancia para la tecnología móvil y ubicua. (Figueroa, 2015)

Por ello, consideramos relevante poder reproducir la dimensión espacial y física de la interacción que se da en la mesa. La mesa permite organizar la información durante la interacción, además de facilitar el intercambio físico de información y de acción de los participantes durante las sesiones de críticas de mesa. A partir de las consideraciones y el análisis de nuestras observaciones, hemos diseñado una interfaz que busca reproducir la interacción de la crítica de mesa que hemos llamado TraceSpace (c) ${ }^{8}$. En la Figura 6 puede verse una imagen de sus elementos característicos: el área de trabajo puede extenderse a la izquierda o a la derecha, la barra de herramientas contiene todas las funciones principales de dibujo, y el papel de calco (tracing), en una superficie trasluciente para añadir anotaciones. Las anotaciones pueden añadirse manualmente con toque (mano o lápiz), y los dibujos y calcos pueden moverse con la mano en cualquier dirección, así como superponerse o eliminarse, todo esto emulando la manera física en la cual esta interacción se da en la mesa de trabajo y con los materiales análogos típicamente usados en el trabajo de diseño tradicional, el papel y el lápiz. 

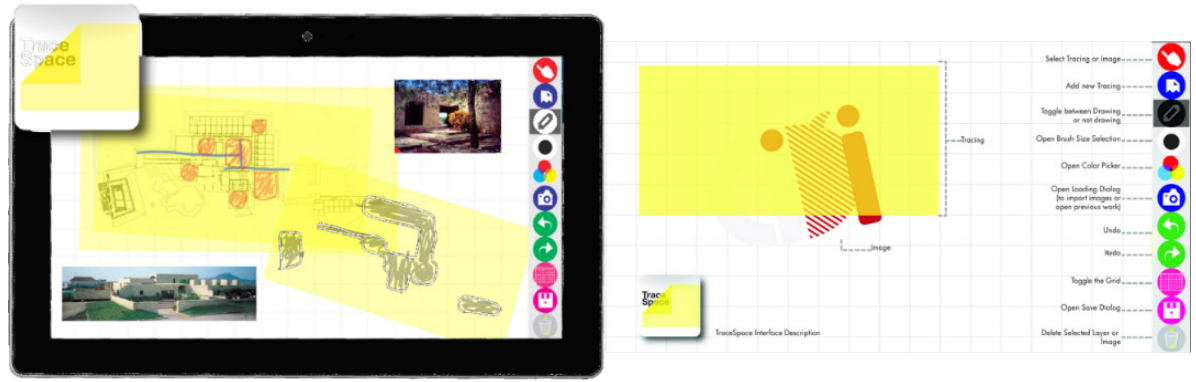

Figura 6: Ventana de TraceSpace (C) mostrando sus elementos característicos. El área de trabajo puede extenderse a la izquierda o derecha, la barra de herramientas tiene todas las funciones principales y el papel de calco (tracing) es una superficie trasluciente que reproduce las características físicas del papel de calco.

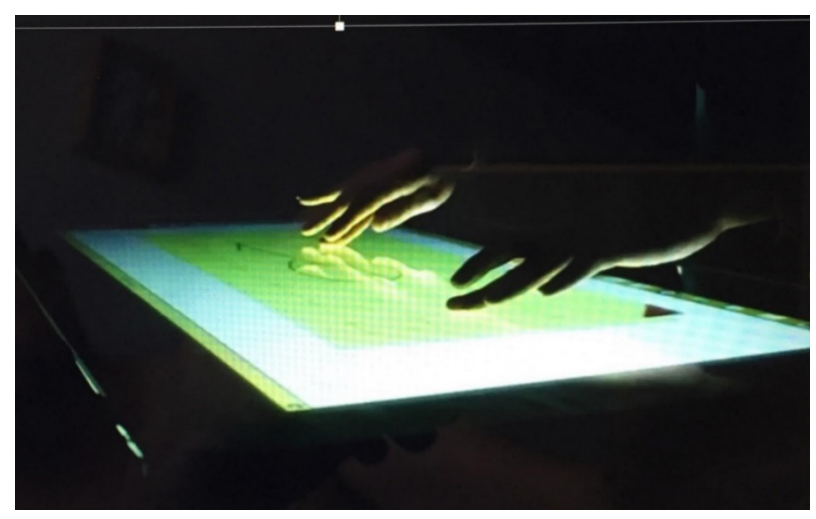

Figura 7: Uso de TraceSpace (C) en una superficie multitoque para replicar el uso de dibujo+papel del calco, de la manera usada en las críticas de mesa. Para un video mostrando la operación de la aplicación, acceda a https://bit. ly/2T1F1gx

La aplicación ha sido diseñada para operar en entornos de táctiles (Figura 7) con lo cual se puede reproducir el entorno físico de trabajo de la mesa de dibujo análogo. La aplicación ha sido diseñada también para operar en todos los sistemas operativos comercialmente disponibles, tanto para computadoras como para tabletas y teléfonos celulares, por lo que opera en iOS, Windows, Androide, y sus correspondientes sistemas operativos para tabletas y teléfonos. Esto asegura la portabilidad, y sobre todo la posibilidad de compartir archivos y aplicación tanto de manera sincrónica o asincrónica.

\section{REFLEXIONES FINALES}

Es innegable hoy en día que luego de una historia que empezó como un cauto coqueteo y culminó con una sólida relación aun en progreso, las herramientas de modelado 
digital en arquitectura han llegado a ocupar un espacio ya necesario en la resolución de problemas de diseño. Su capacidad extraordinaria para la simulación y la generación de imágenes cada vez más fieles a la realidad, y la posibilidad de sumar a éstas niveles adicionales de información, ha permitido desarrollar nuevos tipos de práctica que han impactado irreversiblemente la práctica de la arquitectura.

Sin embargo, y como hemos presentado en este texto, estas poderosas herramientas carecen aun de la capacidad de sustituir la riqueza de las imágenes producidas por los medios análogos tradicionales usados por siglos en la práctica del diseño arquitectónico, precisamente porque aquello que se presenta como la fortaleza de las herramientas digitales requiere para producirse de insumos que en las etapas preliminares del proceso de diseño o bien no se dispone, o bien no se han generado aún. La necesidad de imposiciones subjetivas para la formulación de los problemas endemoniados y el espacio de ambigüedad necesario para esa primera etapa creativa, parecen aun estar bien servido con la generación análoga de imágenes producto del dibujo a mano tradicional.

En efecto, hay indicios ya de que contemporáneamente, y luego de años recientes de reinado digital casi absoluto, nos encontramos pasando el umbral hacia una época post-digital (Jacob, 2018), en la cual se revisita el uso del dibujo arquitectónico análogo como una forma de hacer en el mundo, reclamando así su sitial histórico por excelencia para crear, ensayar y escenificar la imagen arquitectónica.

\section{NOTAS}

1. Una versión de este escrito fue presentado en el IX Congreso de la Federación Latinoamericana de Semiótica "Semiótica visual: perspectivas latinoamericanas", 6 al 9 de febrero de 2019, Zacatecas, México. 2. Para 2012, AutoCAD declaraba 12 millones de productos vendidos (en los treinta años desde su introducción al mercado en 1982), y alrededor de 60 millones usando la aplicación en otras formas, incluyendo copias ilegales (Newton, 2012).

3. Traducción del autor.

4. Se define como framing en el proceso de diseño a las acciones destinadas a definir y limitar las variables que son relevantes a la solución de los problemas

5. Traducción del autor.

6. Traducción del autor.

7. El CAD refiere a las prácticas y herramientas asociadas a los programados y equipos utilizados para auxiliar los procesos de diseño de manera digital.

8. TraceSpace fue desarrollado con un financiamiento del programa FIPI del Decanato de Estudios Graduados e Investigacion y de la Escuela de Arquitectura, ambos del Recinto de Rio Piedras de la Universidad de Puerto Rico. La investigación y desarrollo se hizo conjuntamente con la dirección del Prof. Rafel Arce Nazario, y la participación de los Estudiantes Edgardo Agosto, Jeffrey Chang, Alberto José de la Cruz, Roberto Feliu, Rebecca Leandra, Omar Xavier Nieves, Jorel Sanchez, Rafael Santiago.

\section{REFERENCIAS BIBLIOGRÁFICAS}

AIACC. (2014). Integrated project delivery: an updated working definition. American Institute of Archi- 
tects, California Council Sacramento, California.

ALBERTI, L. B. (1991). De Re Aedificatoria. Fuentes de arte.

ALBRECHTSEN, H., ANDERSEN, H. H. K., BØDKER, S., \& PEJTERSEN, A. M. (2001). Affordances in Activity Theory and Cognitive Systems Engineering. Learning (Vol. 1287).

ANSARI, I. (2013). Interview: Peter Eisenman | Thinkpiece | Architectural Review. Retrieved January 15, 2019, from http://www.architectural-review.com/rethink/interview-peter-eisenman/8646893.fullarticle

BARFIELD, W., \& FURNESS, T. A. (1995). Virtual environments and advanced interface design. Oxford University Press, USA.

CASAKIN, H. (2017). The Use of Metaphors as Design Communication Tools in an Architectural Team. NEW ARCH-INTERNATIONAL JOURNAL OF CONTEMPORARY ARCHITECTURE. https://doi.org/10.14621/tna.20170206

CASAKIN, H, \& GOLDSCHMIDT, G. (1999). Expertise and the use of visual analogy: implications for design education. Design Studies, 20(2), 153-174. Retrieved from http://www. sciencedirect.com/science?_ob=ArticleURL\&_udi=B6V2K-3VVTCCH-5\&_user $=7153270$ \&_coverDate $=03 / 31 / 1999 \& \_r d o c=1 \& \_f m t=\& \_o r i g=$ search\&_sort $=d \& v i e w=c \& \_a c c t=C 000059122 \& \_$ version $=1$ \&_urlVersion $=0 \&$ \&userid $=7153270 \& \mathrm{md} 5=4 \mathrm{~d} 0 \mathrm{ff} 00878 \mathrm{cc} 107815471930 \mathrm{ee} 211100$

EISENMAN, P. (1992). Visions unfolding: architecture in the age of electronic media. Domus. https://doi.org/10.1007/s13224-014-0668-3

ENGESTRÖM, Y., MIETTINEN, R., \& PUNAMÄKI, R.-L. (1999). Perspectives on activity theory. Cambridge University Press.

FIGUEROA, H. (2015). El cuerpo, los toques y el espacio multimediático. Retrieved December 13, 2015, from http://dialogoupr.com/noticia/puertorico/el-cuerpo-los-toques-y-el-espacio-multimediatico/

GAVER, W., BEAVER, J., \& BENFORD, S. (2003). Ambiguity as a resource for design. Proceedings of the Conference on Human Factors in Computing Systems CHI 03, computings(5), 233. Retrieved from http://eprints.gold.ac.uk/272/

GOLDSCHMIDT, G. (2017). Manual Sketching: Why Is It Still Relevant? In The Active Image (pp. 77-97). Springer.

HAM, J. J., \& SCHNABEL, M. A. (2011). Web 2.0 virtual design studio: social networking as facilitator of design education. Architectural Science Review, 54(2), 108-116.

HAN, J. Y. (2005). Low-cost multi-touch sensing through frustrated total internal reflection. In Proceedings of the 18th annual ACM symposium on User interface software and technology (pp. 115-118).

New York, New York, USA: ACM Press. https://doi.org/10.1145/1095034.1095054

HANDY, C. (1993). Understanding Organizations. Penguin UK.

ISHII, H. (2008). Tangible bits: beyond pixels. In Proceedings of the 2 nd international conference on Tangible and embedded interaction (pp. xv--xxv).

ISHII, H., \& ULLMER, B. (1997). Tangible bits: towards seamless interfaces between people, bits and atoms. In Proceedings of the ACM SIGCHI Conference on Human factors in computing systems (pp. 234-241).

JACOB, S. (2018). Architecture Enters the Age of Post-Digital Drawing - Metropolis. Retrieved January 18, 2019, from https://www.metropolismag.com/architecture/architecture-enters-age-post-digital-drawing/

KUUTTI, K. (1996). Activity theory as a potential framework for human-computer interaction research. Context and Consciousness: Activity Theory and Human-Computer Interaction, 17-44.

LEWIS, B. (2000). Talking to Texts and Sketches: The Function of Written and Graphic Mediation in Engineering Design. Business Communication Quarterly. https://doi. org/10.1177/108056990006300212

MAYNE, T. (2005). Change or perish. Retrieved December 13, 2015, from http://www.aia.org/ 
aiaucmp/groups/aia/documents/document/aias076762.pdf

MITCHELL, W. J. T. (1984). What Is an Image? New Literary History, 15(3), 503-537. https:// doi.org/10.2307/468718

MOORE, T. J.; MILLER, R. L.; LESH, R. A.; STOHLMANN, M. S. \& KIM, Y. R. (2013). Modeling in Engineering: The Role of Representational Fluency in Students' Conceptual Understanding. Journal of Engineering Education. https://doi.org/10.1002/jee.20004

NEWTON, R. (2012). The Autodesk big picture is a rose colored paint-by-number. Retrieved January 17, 2019, from https://gfxspeak.com/2012/03/29/autodesk-2012-by-the-numbers/

NORMAN, F. (2001). Towards a paperless studio. In The ARCC Spring Research Meeting Architectural Research Centers Consortium (pp. 85-91). Blacksburg, Virginia.

OXMAN, R. (2017). The role of the image in digital design: processing the image versus imaging the process. In The Active Image (pp. 133-156). Springer.

RITTEL, H. (1971). Some principles for the design of an educational system for design. Journal of Architectural Education, XXVI(1 and 2).

RITTEL, H. W. J. (1988). The reasoning of designers. IGP.

SALAMA, A. (1995). New trends in architectural education: Designing the design studio. ARTI-ARCH. SCHÖN, D. (1992). Designing as reflective conversation with the materials of a design situation. Research in Engineering Design, 3(3), 131-147.

SCHÖN, D. A. (1987). Educating the reflective practitioner : toward a new design for teaching and learning in the professions. The Jossey-Bass higher education series (1st ed.). San Francisco: Jossey-Bass. 